\title{
Relocations and one-time disturbance fail to sustainably disperse non-breeding common ravens Corvus corax due to homing behaviour and extensive home ranges
}

\author{
Pascal Marchand ${ }^{1,2}$ (1) $\cdot$ Matthias-Claudio Loretto ${ }^{3,4,5} \cdot$ Pierre-Yves Henry $^{6,7} \cdot$ Olivier Duriez $^{8} \cdot$ Frédéric Jiguet $^{7}$. \\ Thomas Bugnyar $^{3,4} \cdot$ Christian Itty $^{1}$
}

\begin{abstract}
Some protected species have benefited from human activities to a point where they sometimes raise concerns. However, gaps in knowledge about their human-related behaviour hamper effective management decisions. We studied non-breeding common ravens Corvus corax that aggregated and predated livestock in the surroundings of a landfill. Combining several approaches, we first assessed the effectiveness of relocations at distances ranging from 20 to $240 \mathrm{~km}$, and of one-time disturbance consisting in non-lethal shots performed at night roosts and at surrounding foraging areas during two consecutive evenings, in reducing ravens' presence at the landfill. Then, we documented the spatial ecology of both relocated ravens and control ones (i.e. released in situ). Although the return probability widely varied with relocation distance and time after release, homing behaviour (87/102 relocated ravens marked with wing tags [85.3\%] returned to the landfill in 3 years) prevented relocations from sustainably reducing the presence of ravens. Likewise, one-time disturbance only decreased ravens' abundance during a few hours. These results could be related to the extensive movements of ravens equipped with GPS trackers. The total area occupied by control ravens reached $40,492 \mathrm{~km}^{2}$, i.e. $7.4 \%$ of the area of France and $21.7 \%$ of the French species distribution range. Individuals used smaller home ranges $\left(\min =84 ; \max =1814 \mathrm{~km}^{2}\right)$, consisting in a network of foraging areas and roosts that they visited. The daily and weekly turnover rates in the observed area of the landfill were high (on average $0.68 \pm 0.2$ and $0.36 \pm 0.17$, respectively) and the actual presence of ravens displayed strong seasonal variation. Hence, one-time/local management actions affected only a limited proportion of the population, partly explaining their small impact. Our study provides information needed to improve future management plans in a context of increasing ravens populations and conflicts with human activities.
\end{abstract}

Pascal Marchand

pascal.marchand@oncfs.gouv.fr

1 Délégation Régionale Occitanie, Office National de la Chasse et de la Faune Sauvage, Actisud Bâtiment 12, 18 rue Jean Perrin, F-31100 Toulouse, France

2 Unité Ongulés Sauvages, Office National de la Chasse et de la Faune Sauvage, Les Portes du Soleil, 147 avenue de Lodève,

F-34990 Juvignac, France

3 Department of Cognitive Biology, University of Vienna, Althanstrasse 14, 1090 Vienna, Austria

4 Core Facility for Behaviour and Cognition, Konrad Lorenz Forschungsstelle, University of Vienna, Fischerau 11, 4645 Grünau im Almtal, Austria
5 Institute of Wildlife Biology and Game Management, University of Natural Resources and Life Sciences, Gregor-Mendel-Straße 33, 1180 Vienna, Austria

6 Mécanismes adaptatifs et Evolution (MECADEV UMR 7179), Muséum National d'Histoire Naturelle, Centre National de la Recherche Scientifique, 1 avenue du Petit Château, F-91800 Brunoy, France

7 Centre d'Ecologie et des Sciences de la Conservation (CESCO UMR 7204), Centre de Recherches sur la Biologie des Populations d'Oiseaux, Muséum National d'Histoire Naturelle, Centre National de la Recherche Scientifique, Sorbonne Université, Bâtiment 135, CP 135, 43 rue Buffon, F-75005 Paris, France

8 Centre d'Ecologie Fonctionnelle et Evolutive (CEFE UMR 5175), Campus du CNRS, 1919 Route de Mende, F-34293 Montpellier, cedex 5, France 
Keywords Corvids - Space use - Movements · Home range $\cdot$ Human/wildlife conflicts · Wildlife/livestock interactions · Management of protected species · GPS telemetry

\section{Introduction}

The encroachment of human activities on wildlife habitats has resulted in dramatic demographic and distributional consequences for numerous species justifying important conservation efforts (Vitousek et al. 1997; Palumbi 2001). Some species sometimes benefit from this protection, can develop new behaviours and/or take advantage of human activities (e.g. livestock farming), anthropogenic food sources (e.g. crops, landfills, urban rubbish), human-related reproductive habitats, predator-free areas and/or conservation of other endangered species. Some populations/species increase in the vicinity of human activities and/or urban areas (Gehrt et al. 2010 in carnivores, Margalida and Colomer 2012 in raptors, Marzluff 2001 for a review in birds) to the point that some of them now cause locally important damage, and raise security, public health, conservation and hence, economic and management concerns (Messmer 2000; Conover 2002; Courchamp et al. 2003; Woodroffe et al. 2005; Adams and Lindsey 2016). Among these controversial situations, livestock depredation is probably the most common cause of human-wildlife conflicts, with large carnivores being of particular concern in this context (Thirgood et al. 2005). Predation on young individuals (e.g. lambs, calves) by protected raptors and corvids, though generally less severe and patchily distributed, can locally have significant economic consequences for individual farmers and trigger controversy, justifying management attempts worldwide (Matchett and O'Gara 1987; Phillips and Blom 1988; Avery and Cummings 2004 on golden eagle Aquila chrysaetos, bald eagle Haliaetus leucocephalus and black vulture Coragyps atratus in USA; Davies 1999 on black eagle Aquila verreauxii in South Africa; Ruiz-Olmo et al. 2006; Margalida et al. 2014 on common raven Corvus corax and griffon vulture Gyps fulvus in Spain; Donázar et al. 2016 for a review of southern Europe).

Depending on the trade-off between the preservation of direct human interests and drawbacks for species conservation, management strategies have been developed to reduce or resolve conflicts (e.g. disturbance, relocations, egg pricking, nest destructions, non-lethal or lethal shots; Breitenmoser et al. 2005; Adams and Lindsey 2016). Theoretically, all of these strategies rely on knowledge of the species' ecology raising concerns in the area where conflicts occur (e.g. spatial ecology and distribution, population dynamics; DeStefano and DeGraaf 2003; Blackwell et al. 2016). In practice, this knowledge is often surprisingly scarce as wildlife ecologists traditionally focus research on sites relatively free of human influences. However, conflict species often adjust their behaviour in anthropized environments (see Lowry et al. 2012 for a review), so that management strategies relying on knowledge gained from undisturbed areas are not always as efficient as expected. In addition, the monitoring of wildlife in urban or human-dominated areas is often difficult (e.g. equipment degradation, private property) and only recently benefited from advanced technology-based methods allowing to overcome these challenges, such as camera traps or biologging devices and sensors (DeStefano and DeGraaf 2003; Cagnacci et al. 2010; Anton et al. 2016). As a result, little is known on the way to effectively mitigate the concerns locally raised by some species as the efficiency of previous management operations that have been tested were rarely evaluated and reported.

In the present study, we focused on a population of nonbreeding common raven Corvus corax in the surroundings of an open landfill in central France. This raven population causes damage on livestock farming around the landfill (detailed hereafter) which lead the French Authorities to launch regulation actions (disturbance, relocation) in an attempt to reduce damage to livestock farming. Authorization to perform these regulations was granted with the condition that the effectiveness of the management actions be assessed. It therefore provided a unique opportunity to document the spatial ecology of non-breeding ravens and their response to the tested management actions. Indeed, knowledge on the spatial and behavioural ecology of these non-breeding flocks of common ravens remains scarce. As a result, little is known about methods required to mitigate the negative impacts these flocks can locally have on livestock farming activities, e.g. predation on livestock newborns (Rowley 1969; Skarphedinsson et al. 1990; Ruiz-Olmo et al. 2006), and on the conservation of endangered species, e.g. predation on juvenile desert tortoises Gopherus agassizii in the Mojave desert (Kristan and Boarman 2003), on eggs and chicks of the snowy plover Charadrius nivosus in California, (Peterson and Colwell 2014). A variety of lethal and non-lethal approaches have been used to reduce ravens' presence (i.e. altering ravens habitats, e.g. by limiting human-subsidized food/water, remove/cull predatory ravens), with varying degrees of success when assessed and reported (Skarphedinsson et al. 1990; Boarman 2003; U.S. Department of the Interior Fish and Wildlife Service et al. 2008; Peterson and Colwell 2014).

We assessed the efficiency of two non-lethal management techniques that were recommended by the French Authorities to reduce ravens' abundance in the landfill: (i) relocations at distances ranging from 20 to $240 \mathrm{~km}$ from the study area, and (ii) disturbance at night roosts and at surrounding foraging areas. We combined a traditional mark-resight monitoring, 
specific count sessions and data collected by camera traps to evaluate the return rate, the time elapsed between relocation and return to the landfill, and the threshold distance preventing relocated ravens from returning to the landfill. We then relied on the same mark-resighting protocols performed on the days before and after one-time roost disturbance to check their effectiveness at sustainably decreasing raven abundance at the landfill. Next, we assessed the temporal variation in landfill use by ravens (i) by computing the annual variation in the daily and weekly turnover rates of ravens marked with wing tags and (ii) by evaluating the distribution of control ravens (i.e. released in the studied landfill) marked with GPS trackers according to the distance to the landfill. Finally, data from GPS trackers provided insights about the range occupied by the studied population, and about temporal and interindividual variation in space use and in movements of both control and relocated ravens.

\section{Material and methods}

\section{Study species, area and population}

Ravens have a long history of persecution by humans, leading to dramatic decrease in population abundance until the end of the nineteenth century (i.e. ravens were almost extinct in central Europe in the 1950s; Haffer and Kirchner 1993). As in most European countries, the common raven was declared as a protected species in 1976 in France, resulting in an increase in numbers and in distributional ranges (Delestrade 2002). Breeding common ravens form long-term monogamous pairs that defend a territory year-round (often $\geq 10 \mathrm{~km}^{2}$; Rösner and Selva 2005; Rösner et al. 2005). To become a breeder, sexually mature individuals have to find a partner and a territory. This generally occur when ravens reach 34 years old (Ratcliffe 1997; Webb et al. 2009) but may take more than 10 years in some individuals/populations (Loretto and Bugnyar, unpublished data). During this prolonged nonbreeding stage, the ecology and behaviour of common ravens largely differ from those of breeding pairs. Non-breeding ravens behave like floaters, often found in flocks of a few to a few tens of individuals, characterized by temporarily dynamic social bonds and a high propensity to vagrancy (Braun and Bugnyar 2012; Loretto et al. 2016a, 2017). These floaters often rely on human food sources such as farms and landfills and flocks generally gather at these feeding sites or at specific roosting trees (Heinrich et al. 1994; Restani et al. 2001; Webb et al. 2004; Loretto et al. 2016b, 2017). An important inter-individual heterogeneity in space use has been reported in studies relying on traditional monitoring systems (i.e. mark-resight, recovery of dead animals, VHF telemetry; Boarman and Heinrich 1999a; Loretto et al. 2016a).
We collected data on the common raven Corvus corax population inhabiting the surroundings of the non-hazardous waste storage centre from Saint-Flour (opened in 1975), in central France $\left(45^{\circ} 03^{\prime} 09.84 \mathrm{~N}\right.$; $03^{\circ} 05^{\prime} 56.78 \mathrm{E}$; altitude: $835 \mathrm{~m}$ a.s.1.). This raven population concentrated and increased during the last decade after 28 out of 38 waste storage centres in the surroundings were closed between 2000 and 2014. This raven population causes damage on traditional free-ranging livestock farming around the landfill. Between 1997 and 2014, 84 attacks from ravens (on sheep, pig, cattle and poultry, mostly on newborns but also on adults) were reported at 53 farms located within a $80-\mathrm{km}$ radius around the landfill, in addition to non-measurable indirect effects (e.g. production decrease, abortions; Mure 2014). The depredation rate by common ravens in the two most impacted farms was estimated to 2-3 newborn pigs killed per day when births occurred and 20 lambs killed per year. Damage led some farmers to change their husbandry techniques or the type of livestock (Mure 2014).

Despite legal protection in France (Ministerial decrees-17 April 1981, 29 October 2009), between 2009 and August 2013, the authorities proposed several overriding management approaches to reduce the presence of ravens and depredation rate around the landfill. These approaches consisted of scaring by sound systems, use of scarecrows, restricted access to human-subsidized food in the landfill, non-lethal shots at surrounding roosts and relocations. As captured birds were not marked and variation in raven abundance and in depredation rate was not recorded, the effectiveness of these actions could not be evaluated. However, all of them seemed inefficient in the long term (P. Lalo, personal communication).

\section{Management operations}

Since August 2013, the authorities have engaged research aiming to evaluate the results of forthcoming management operations, i.e. relocations and roost disturbance.

In total, 325 ravens were captured using three crow traps (cages with a small opening at the roof; $\mathrm{L} \times \mathrm{W} \times \mathrm{H}: 3 \times 2 \times$ $2 \mathrm{~m}$ ) located $<500 \mathrm{~m}$ from the landfill, baited with meat and raven decoys. After being marked (see below), ravens were released one by one (1) in the landfill (control group) or (2) at variable distances from the landfill $(20-30,40-50,50-60,60$ 70, 80-90, 150 and $240 \mathrm{~km}$; with replicates for most distance classes; see Table 1 and Electronic Supplemental Material ESM 1). Control and relocated ravens were randomly chosen within the captured ravens. Relocation distances represented a trade-off between the expected benefits in terms of reduction of ravens presence and damage around the landfill and the economic, technical, ethical and regulatory feasibility of relocations.

Disturbance consisted of non-lethal shots at night roosts and at foraging areas in the surrounding of the landfill. They 
Table 1 Number of non-breeding common ravens captured in the waste storage centre of Saint-Flour (central France) and marked with the different tagging systems (LR only = only with leg rings; $\mathrm{WT}=$ at least with wing tags; GPS = GPS trackers). NB: We sometimes added tags on some ravens recaptured. Besides, we often combined tagging systems (e.g. LR and WT, LR and GPS), explaining that the total number of ravens equipped is higher than the total number of birds captured

\begin{tabular}{llll}
\hline Release distance $(\mathrm{km})$ & LR only & WT & GPS \\
\hline Control & 34 & 56 & 18 \\
$20-30$ & 19 & 10 & 1 \\
$40-50$ & 21 & 12 & 2 \\
$50-60$ & 58 & 11 & 0 \\
$60-70$ & 14 & 16 & 2 \\
$80-90$ & 4 & 15 & 4 \\
150 & 42 & 30 & 4 \\
240 & 1 & 5 & 1 \\
Total & 193 & 155 & 32 \\
\hline
\end{tabular}

were performed by six wildlife management professionals during two consecutive evenings, i.e. 23 and 24 July 2016.

Note that the efficiency of the culling of 235 unmarked ravens that was performed in the surroundings of the landfill between 2013 and 2016 in reducing ravens abundance and damage was not evaluated as abundance and/or depredation levels before these operations were not available.

\section{Raven monitoring}

We aged the ravens captured as part of management operations (see above) based on plumage and inside upper mandible colors, following Demongin (2005) and Blasco (see http:// aulaenred.ibercaja.es). Three age classes could be distinguished: juveniles, 1 year old, and $\geq 2$ years old. In 2013 and 2014, we marked ravens with numbered leg rings (one coloured plastic ring on one leg, with an unique code readable from 5 to $6 \mathrm{~m}$ with camera traps or until $250 \mathrm{~m}$ with a spyglass $[\times 60]$; total weight $=2.5 \mathrm{~g}$ ). Since 2015 , we added coded wing tags (7.5-12.5 g), VHF transmitters (Holohil; 28. $5 \mathrm{~g}$ ) and/or GPS-GSM trackers (Ecotone Duck 4-30 g; Ecotone saker H-20 g; Ornitela EE-25-25 g; backpack harness), while keeping the total weight of equipment $<3 \%$ of ravens' body mass (see Table 1 for details on the total number of birds marked with the different systems). We programmed GPS trackers to record ravens' positions depending on battery power level with at least one position every hour during daytime and until the beginning of the night to record the roosting position. The average duration of the GPS monitoring was 440 \pm 318 days. Tracking ended because of bird death $(n=8$ individuals; this proportion being comparable with natural mortality in other populations, see Webb et al. 2004), tag loss $(n=3)$ and battery/tag failure $(n=7)$. Only ravens with GPS monitoring $>6$ months $(n=16)$ were included in analyses.
We collected resighting data using several protocols depending on tagging systems. First, recaptures (64 individuals in 1322 days with traps opened) and photos from the two camera traps deployed in October 2015 on the waste unloading dock (i.e. the most attractive point in the landfill; 4188 observations with marked ravens in 448 days with camera traps active) provided observations of individuals marked with leg rings or wing tags. Second, between September 2015 and December 2017, during human-free periods (e.g. before landfill staff arrival in the morning, during their lunchtime break or after their departure in the evening) of working days with favourable weather (representing around $2 \mathrm{~h}$ per day during 333 days), an observer identified ravens marked with wing tags (using a $\times 20$ to $\times 60$ telescope) from an elevated point with a panoramic view over the landfill and surrounding bocage (around 65 ha, i.e. a larger area than camera traps). Third, during 87 of these $2 \mathrm{~h}$ periods randomly distributed within the resighting period, the same observer performed count sessions repeated every 15 min ( 8 times per $2 \mathrm{~h}$ resighting period). During these sessions, all the ravens landed on a restricted waste area of the landfill (around $1 \mathrm{ha}$ ) were counted and individuals marked with wing tags were identified (those marked with leg rings only being considered as unmarked in analyses as individual identification was not possible).

\section{Assessment of management actions}

\section{Relocations}

For each individual marked with wing tags, data from the three resighting protocols (see above) were transformed into a binomial response variable (i.e. daily resighting history) with 0 coding for days before control/relocated ravens were resighted in the landfill, and 1 coding for days after the first resighting in the landfill (i.e. after return for relocated ravens). We then used a general linear model with binomial error to model the probability that control/relocated ravens were resighted in the landfill according to release distance and time after release. We focused on wing-tagged birds as preliminary analyses revealed that the resighting probability of leg-ringed ravens, relying on camera traps and recaptures only, was far less than the resighting probability of wing-tagged birds (see "Results").

\section{Disturbance at night roosts and at foraging areas}

To assess the ability of non-lethal shots at night roosts and surrounding foraging areas to reduce ravens abundance in the landfill, we used the average number of wing-tagged birds identified during the specific count sessions (performed early in the morning and just before roost disturbance in the evening), or during the $2 \mathrm{~h}$ resighting periods performed each day. Both indexes allowed us to monitor the variation in the abundance of ravens actually present in the study area during the 2 days before, 2 days during and 5 days after roost disturbance. 


\section{Temporal variation in landfill use}

To estimate the proportion of the raven population using the landfill every day, we used the daily proportion of marked ravens observed at the landfill each day, depending on tagging system (leg rings or wing tags) and control/relocated status.

To investigate the extent to which the identity of ravens actually observed at the landfill changed from one day to the next, or from one week to the next, we relied on observations of wingtagged ravens only and computed the daily and weekly turnover

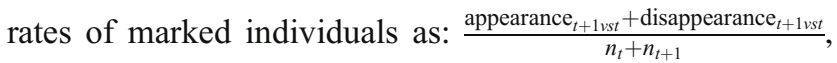
where $t$ is a focal day or week, appearance $e_{t+1}$ vs $t$ is the number of wing-tagged ravens observed on day/week $t+1$ but not observed on day/week $t$, disappearance $e_{t+1}$ vs $t$ is the number of wing-tagged ravens observed on day/week $t$ but not observed on day/week $t+1$ and $n$ is the total number of wing-tagged ravens identified in the landfill during $t$ or $t+1$. The temporal variation of these turnover rates were modelled using General Additive Models (GAM).

Finally, to document space use by ravens using the landfill, we evaluated the distribution of control ravens marked with GPS trackers according to the distance to the landfill. We performed this analysis with all the GPS data available or only during days when control ravens had been located at least once within the $<1 \mathrm{~km}$ around the landfill to distinguish days when they were present or absent in the study area.

\section{Temporal variation and differences in space use and movement characteristics between control and relocated ravens}

To assess whether space use differed between relocated ravens and those released in situ (control), we used data from GPS trackers to define the ranges occupied by both groups of ravens, and distinguished periods before and after return to the studied landfill for relocated ones.

Using the same data set, we also computed the average and maximum distances travelled by ravens in $1 \mathrm{~h}$ (i.e. linear distance between two consecutive locations), and the average and maximum cumulative distances travelled per day during the monitoring of both control and relocated ravens. We investigated the yearly variation in movements of control ravens by modelling the variation in the daily distances they travelled (log-transformed) using General Additive Mixed effects Models (GAMM) to account for repeated measurements on the same individuals.

Finally, we derived the space use of GPS-tagged ravens from individual utilization distribution (UD) computed using the Biased Random Bridge approach (BRB; Benhamou 2011). This method is based on a biased random walk movement model. It incorporates animal's movement path and time between locations to calculate UD, the probability density function providing likelihood of an animal occurring in each unit of a defined area, i.e. the $500 \mathrm{~m}$ cells of a raster grid, during the monitoring period. It assumes that the animal movement is governed by a drift component (a general tendency to move in the direction of the next location) and a diffusion component (tendency to move in other directions than the direction of the drift). For each individual, we determined the drift component using the locations triplets collected during $3 \mathrm{~h}$, and the diffusion component using the maximum likelihood approach developed by Benhamou (2011). We then defined the home range of each raven as the area including $95 \%$ of the space use estimated by the BRB approach. For both control and relocated ravens, we computed individual home ranges using all the GPS data available, or during defined time periods within their monitoring. Indeed, based on the distance to the landfill and the approach developed by Lavielle (1999, 2005), we segmented individual trajectories in time periods when ravens apparently used different areas (Electronic Supplemental Material ESM 2). Likewise, when possible, we distinguished periods before/ after return to the studied landfill for relocated ravens.

All statistical analyses were performed using $\mathrm{R}$ version 3.4.1 (R Development Core Team 2017), packages "adehabitatHR" and "adehabitatLT" (Calenge 2006) for computing home ranges and movement characteristics of GPS-tagged ravens, and package "mgcv" for generalized additive (mixed) models (Wood 2006). Unless explicitly stated, means are reported \pm standard deviations.

\section{Results}

\section{Capture, mark and resight}

Between August 2013 and March 2017, we caught and marked 325 ravens, among which $72.3 \%$ were juvenile, $25.4 \%$ were 1 year old and only $2.3 \%$ were $\geq 2$ years old. Despite traps being continuously set in the landfill during this period, we recaptured only 64 individuals (19.7\%). In addition, among the 21 control birds captured when they were juvenile and marked with wing tags (between September 2015 and December 2017), 18 (85.7\%) were resighted in the landfill during the same year of capture, whereas only 6 (28.6\%) were recaptured. Likewise, $16(76.2 \%)$ captured as juvenile were resighted in the landfill when they were 1 year old, whereas only $1(4.8 \%)$ of them was recaptured during the same period. When they were 2 years old, $11(52.4 \%)$ of these ravens were resighted in the landfill but none of them were recaptured. These results suggested that juveniles were more prone to be captured than older individuals.

Among control ravens, we identified $92.9 \%$ of the 56 birds marked with wing tags and $73.5 \%$ of the 34 marked with leg 
rings, at least once in the landfill. This value reached $96.4 \%$ for wing-tagged control ravens when including observations collected in other areas (Fig. 1). During days when both monitoring methods were used in the landfill, $50.9 \%$ of the resightings of wing-tagged ravens were provided by direct observations only, $23.2 \%$ by camera traps only and $25.9 \%$ by both systems.

As observations of leg-ringed birds relied on recaptures and data from camera traps only, these firsts results (i.e. agebiased recapture rate and lower resighting probability) suggested that only a partial and biased information could be derived from their monitoring.

\section{Evaluation of management operations}

\section{Relocations}

Among the 269 relocated ravens, 31.1\% of the 167 birds marked with leg rings and $85.3 \%$ of the 102 marked with wing tags were observed back at the landfill during the resighting period. These values dropped to 9.0 and $16.7 \%$ when considering information provided by recaptures only.

The return probability of relocated ravens marked with wing tags largely depended on release distance and on the time after release (Fig. 2). As expected, the shorter the release distance, the higher the return probability, and the shorter the time to return for a given proportion of birds. Interestingly, the return probability was significantly reduced in the long term for release distances $\geq$ $150 \mathrm{~km}$ (return probability $<0.5$ after 600 days), but none of the distances tested resulted in a null return probability.

\section{Disturbance}

The non-lethal shots performed at night roosts and surrounding foraging areas in the landfill on the evenings of the 23 and 24 July 2016 had a very limited influence on ravens abundance (Fig. 3). The average number of birds counted on a restricted area of the landfill during specific sessions reached values between 7 and 72 in mornings and between 74 and 88 in evenings of the 3 previous days. These values dropped to 4 and 12 in mornings and between 27 and 55 in evenings of the 2 days following operations. Similarly, the number of marked ravens identified in the whole landfill during the whole days dropped from values between 27 and 32 before roost disturbance to 11 and 23 during the two following days. However, after roost disturbance, these numbers increased to reach values similar to those observed before (mornings: between 42 and 96; evenings: between 67 and 86; whole day: between 26 and 32). In addition, among the 38 marked ravens that were observed at the landfill during the 3 days before roost disturbance, 35 have also been observed during the 5 following days. Furthermore, the night roosts and the foraging areas used by the 5 ravens monitored with GPS trackers and present in the study area

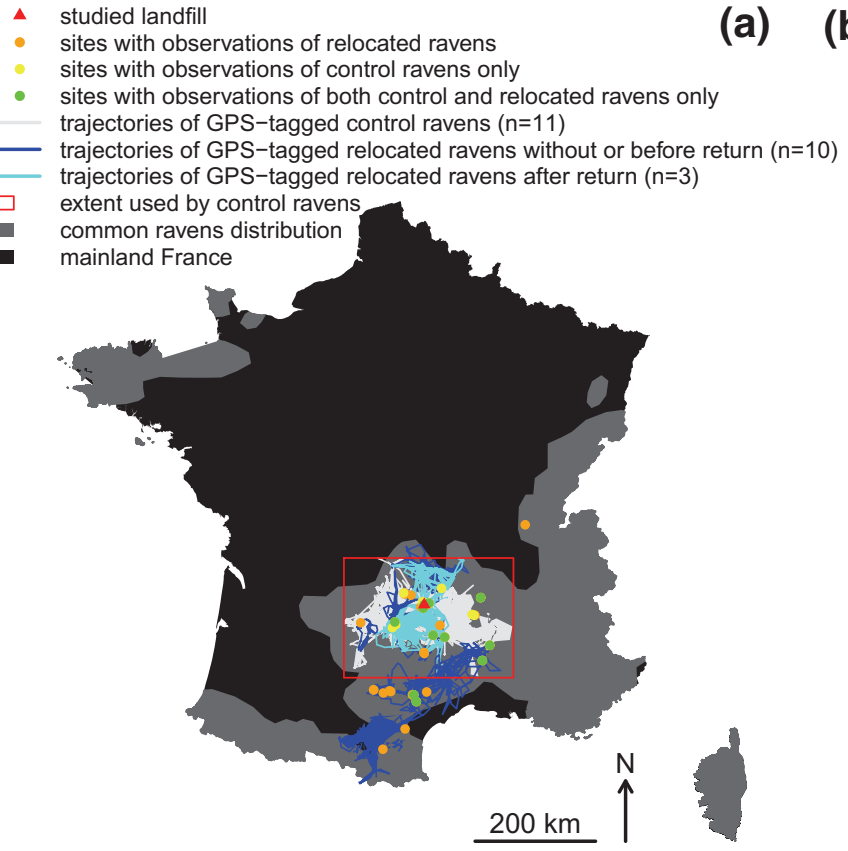

Fig. 1 a Location of the studied landfill (waste storage centre of SaintFlour), of points from which we observed marked common ravens which were released in the studied landfill (= control) or at variable distances (= relocated, see methods), and trajectories of birds equipped with GPS trackers (lines), in mainland France. The species distribution of common raven in mainland France was taken from the International

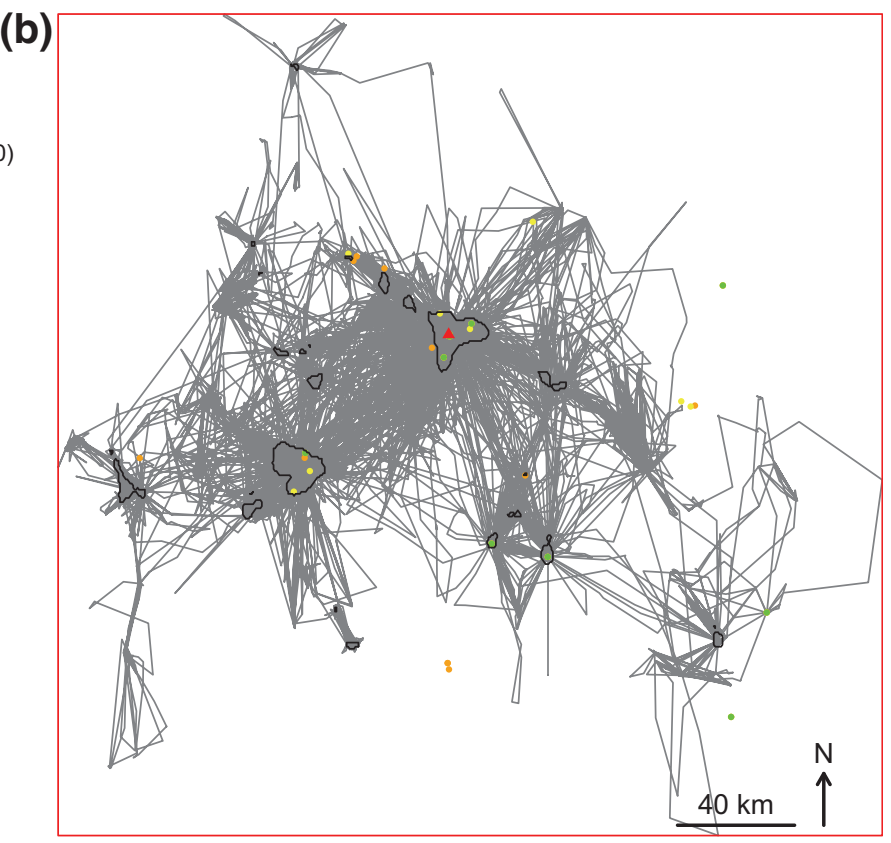

Union for Conservation of Nature Red List of threaten species version 2016-01 (downloaded on 2017-01-25; http://maps.iucnredlist.org). b Focus on the area used by control ravens and their trajectories. The black polygons corresponded to the 22 areas where we identified flocks of non-breeding ravens which we visited during our monitoring period to assess interactions with human activities 
Fig. 2 Variation in the probability that common ravens returned to the landfill where they were captured (waste storage centre of Saint-Flour, central France) in relation to the release distances $(\mathrm{km})$ and time after release (days)

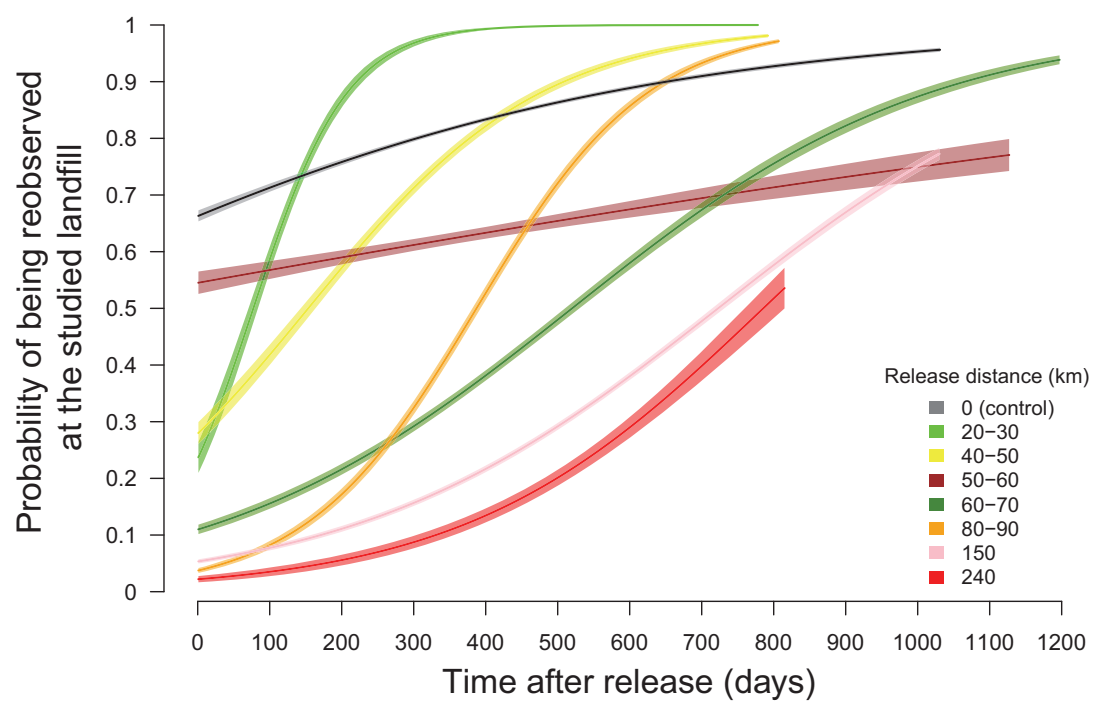

during the roost disturbance were the same before and after these operations (Electronic Supplemental Material ESM 3).

\section{Temporal variation in landfill use by ravens}

The daily proportion of control ravens marked with wing tags observed at the landfill was on average $8.2 \pm 3.6 \%$. However, this proportion displayed strong yearly variation (Fig. 4A). It was minimum in November/December (on average $4.6 \%$ of birds observed at the landfill each day), slightly increased from January to June, until a maximum between June and September (on average $10.1 \%$, but some days with $>25 \%$ ). The same pattern was observed in 2016 and 2017, and with data from wing-tagged birds relocated and returning to the landfill although the average proportions of relocated ravens observed remained lower than those from control ones (Fig. 4B).

Furthermore, a consistent temporal pattern was revealed in the variations of the daily and weekly turnover rates of marked ravens at the landfill (Fig. 5). These daily and weekly turnover rates were on average $0.68 \pm 0.2$ and $0.36 \pm 0.17$, respectively, but peaked between November and February (around 0.8 for daily turnover rate and 0.45 for weekly one) and dropped to their minimum (around 0.6 and 0.3, respectively) during summer (June-September). By contrast, we did not observe any temporal pattern in landfill use by birds marked with leg rings, for which the daily proportions of observations by camera traps remained low, e.g. consistently $<5 \%$ after February 2016 for control ravens (Fig. 4C) and during all the monitoring period for relocated ones (Fig. 4D).

Finally, locations of control ravens equipped with GPS trackers confirmed that ravens were not always in the surrounding of the studied landfill (Fig. 6). Indeed, around 50\% of control ravens' locations were $>10 \mathrm{~km}$ far from the landfill, around $30 \%$ were $>50 \mathrm{~km}$, and the maximum distance at which control birds were located reached $156 \mathrm{~km}$ (Fig. 6A).
By contrast, during days when control ravens were located at least once within $1 \mathrm{~km}$ around the landfill (representing 50\% of days with GPS monitoring), around $70 \%$ of locations were $<1 \mathrm{~km}$ from the landfill and only $10 \%$ were $>10 \mathrm{~km}$ (Fig. 6B).

\section{Differences in space use and movement characteristics between control and relocated ravens}

The total area occupied by the control ravens equipped with GPS trackers was $282 \mathrm{~km}$ wide (west-east) and $199 \mathrm{~km}$ long (north-south; Fig. 1). The area of the minimum convex polygon computed with all these locations was $40,492 \mathrm{~km}^{2}$, i.e. $7.4 \%$ of the area of France and $21.7 \%$ of the species distribution range in France.

The home ranges used by each control raven monitored during a period $>6$ months were smaller and ranged between 84 and $1814 \mathrm{~km}^{2}$ (Table 2).

In addition, these home ranges were not used all year long: we could identify different periods in space use of control ravens, which varied in duration from 54 to 202 days on average, during which the average area occupied by control ravens ranged from 42 to $780 \mathrm{~km}^{2}$. Interestingly, $37 \%$ of these major changes in space use of control ravens occurred in September or October. We could identify 22 different areas successively used by ravens during these periods (Fig. 1). They corresponded to farms ( $n=11$; cattle, sheep, pig, duck), other landfills $(n=5)$, animal/hunting parks $(n=4)$, feeding stations for scavenging birds $(n=2)$, all being characterized by easily available food for ravens.

On average, the daily distance travelled by control ravens ranged between 17 and $32 \mathrm{~km} /$ day. However, this daily distance travelled per day displayed strong yearly variation (Fig. 7). It was stable around 15-20 km/day between October and January, increased to a maximum in March (around $28 \mathrm{~km} /$ day), and 
Fig. 3 Number of common ravens observed at the studied landfill (waste storage centre of Saint-Flour, central France) during the different resighting protocols (see methods) before, during and after non-lethal shots performed in the roosts and surrounding foraging areas during the evenings of the 23 and 24 July 2016

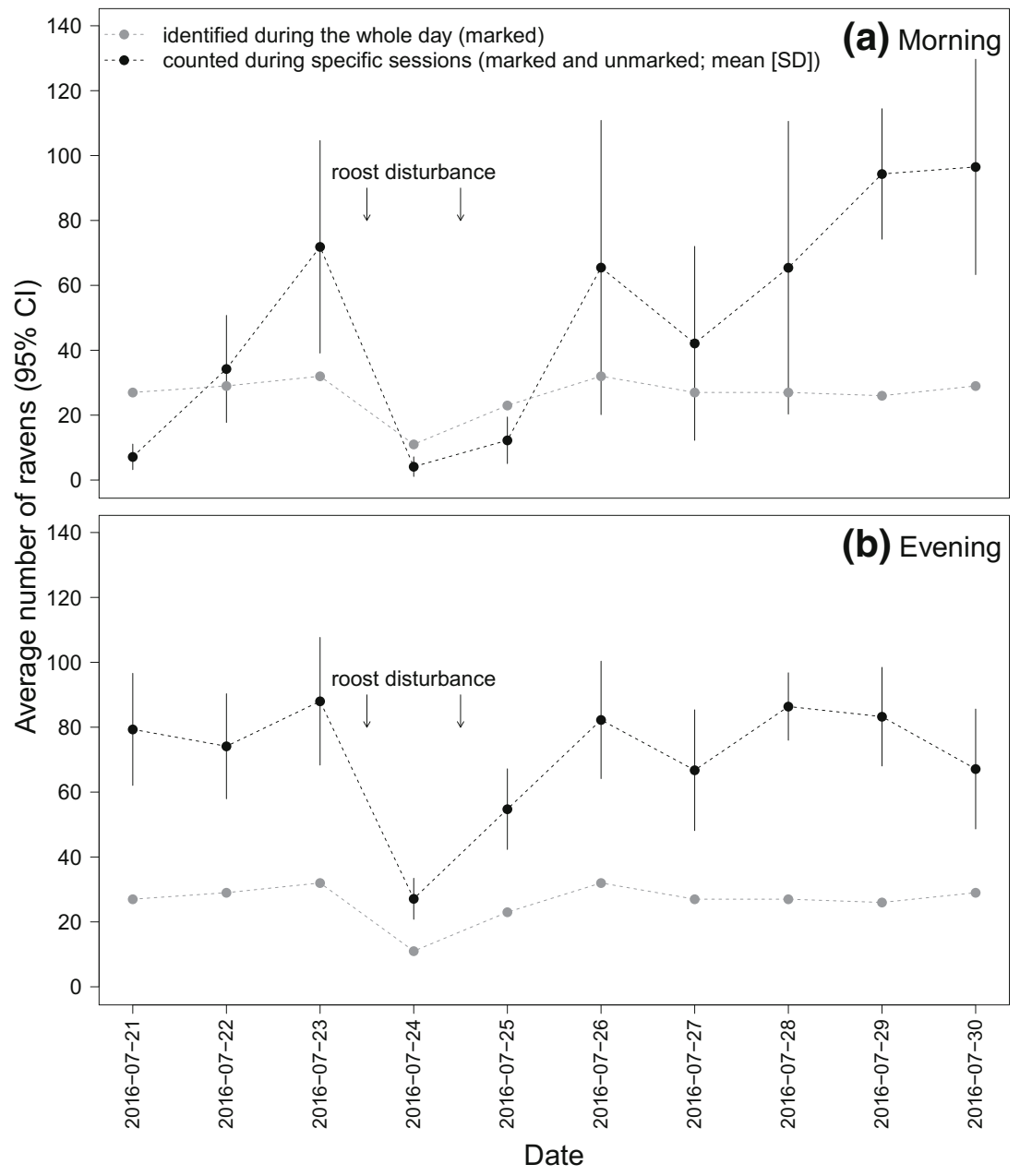

dropped to its minimum in June (around $7 \mathrm{~km} /$ day) before increasing again until October.

As a result of relocations, the total area occupied by relocated ravens was larger than for control birds $\left(65,867 \mathrm{~km}^{2}\right.$, Fig. 1). However, the area of the home range individually used by relocated ravens did not differ from values observed in control birds (mean: $741 \pm 245$; minimum: 548; maximum: $1097 \mathrm{~km}^{2}$; Mann-Whitney test: $U=16 ; p=0.49$ ). Similarly, the average distances relocated ravens travelled per day were in the range of those travelled by control birds $(\min =23 ; \max =37 \mathrm{~km} /$ day). Finally, despite the low number of relocated ravens tracked $>6$ months that returned to the landfill $(n=2)$, we can notice that their trajectories after return reached areas that were not used by control ravens (Fig. 1), resulting in home ranges after return larger than before return (Table 2). Note that their return trip was performed step by step, with an alternation of periods with space use focused on some attractive areas, and sudden changes during which they reached other attractive areas and travelled closer to the studied landfill, until return (data not shown).

\section{Discussion}

Combining mark-resight monitoring, specific count sessions and data from camera traps, we were able to assess the effectiveness of two management approaches tested for reducing the presence of common ravens in a French landfill. Combining these observations with data from GPS trackers improved knowledge on the spatial ecology of common ravens and its temporal variation, leading to essential information for the management of non-breeding common ravens in areas where conflicts with human activities occur.

We found that both relocations of individuals and one-time disturbance at night roosts and surrounding foraging areas only slightly reduced ravens abundance in the short term and had no effect in the long term. Although the number of ravens counted on a restricted area or identified in the entire landfill initially decreased following one-time disturbance, they rapidly returned to the levels observed before disturbance. Likewise, we observed $>85 \%$ of the ravens marked with wing tags returning back in the landfill a few months after they were released, as a result of homing behaviour (Cushing 1941; 
Control

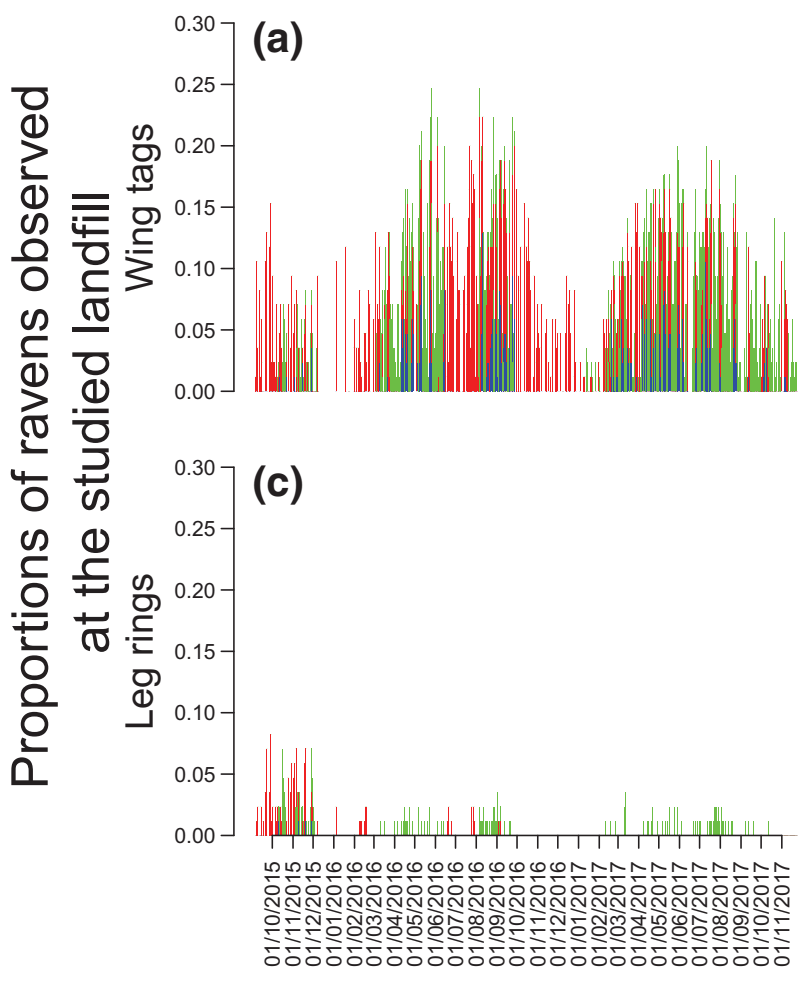

Relocated

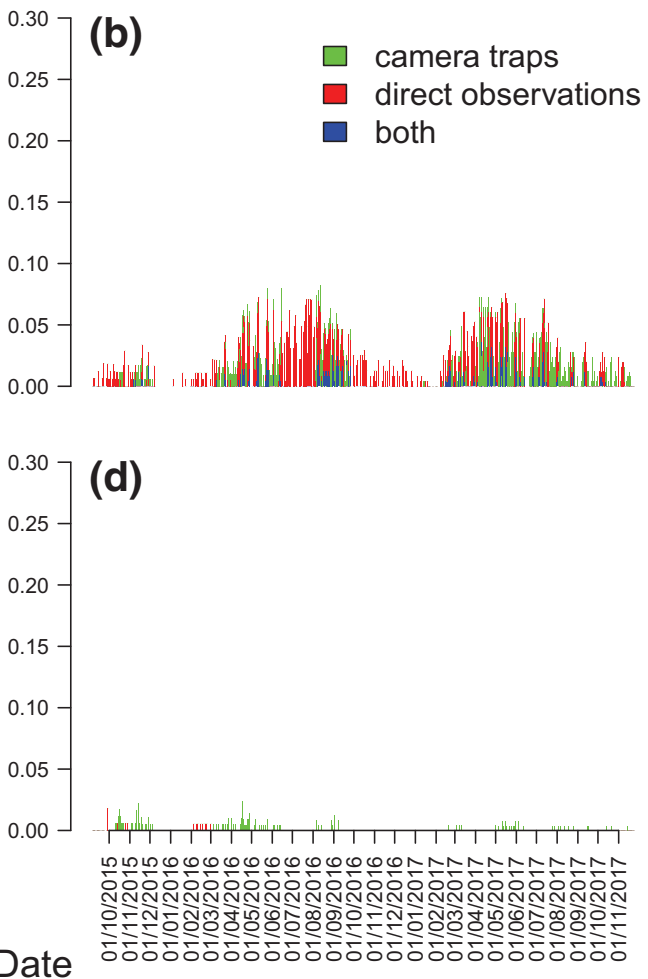

Fig. 4 Temporal variation in the proportion of marked common ravens observed each day in the studied landfill (waste storage centre of Saint-Flour, central France) by the different monitoring systems (see methods) and according to tagging systems and relocation status

Wiltschko and Wiltschko 2003). Below $150 \mathrm{~km}$, increasing the relocation distance only delayed the return of ravens. Releasing the birds at distances greater than $150 \mathrm{~km}$ significantly reduced

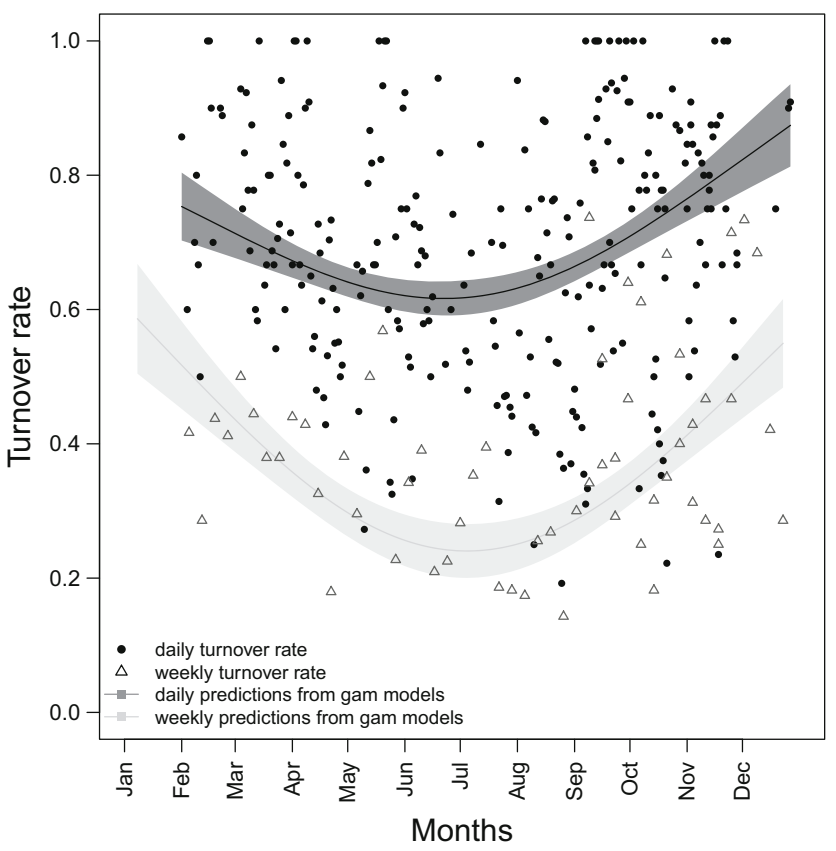

Fig. 5 Temporal variation in the daily and weekly turnover rates of ravens marked in the studied landfill (waste storage centre of Saint-Flour, central France; see methods for details on the computation of turnover rates) the return probability; however, none of the distances tested, as constrained by operation costs and feasibility, were found to prevent homing behaviour. These results are consistent with evaluations of raven and other corvid management programs. In California, Peterson and Colwell (2014) showed that effigies that were tested to scare corvids and reduce their presence near plover Charadrius nivosus nests had only a very local and short-term effect on corvids distribution and abundance. In Spain, despite lethal shots and around 100 common ravens relocated at distances $>200 \mathrm{~km}$, Ruiz-Olmo et al. (2006) reported a temporary decrease in lamb predation but also observations of marked birds returning near the studied landfill and predations that still intensively occurred 5 years later. In a review of the impacts of corvids on the productivity and abundance of the other birds they predate, Madden et al. (2015) found a positive impact of corvids removal in only $16 \%$ of cases studied.

These results can be related to the characteristics of space use and movements of non-breeding common ravens highlighted in our study. We found extensive space use by ravens both in terms of movement capabilities at the hourly or daily scales, and of home ranges and seasonal areas used. The values reported here were larger than those found previously in studies relying on traditional monitoring systems (i.e. mark-resight, recovery of dead animals, VHF telemetry; Skarphedinsson et al. 1990; Boarman and Heinrich 1999a) but consistent with those 
(a) all the GPS locations

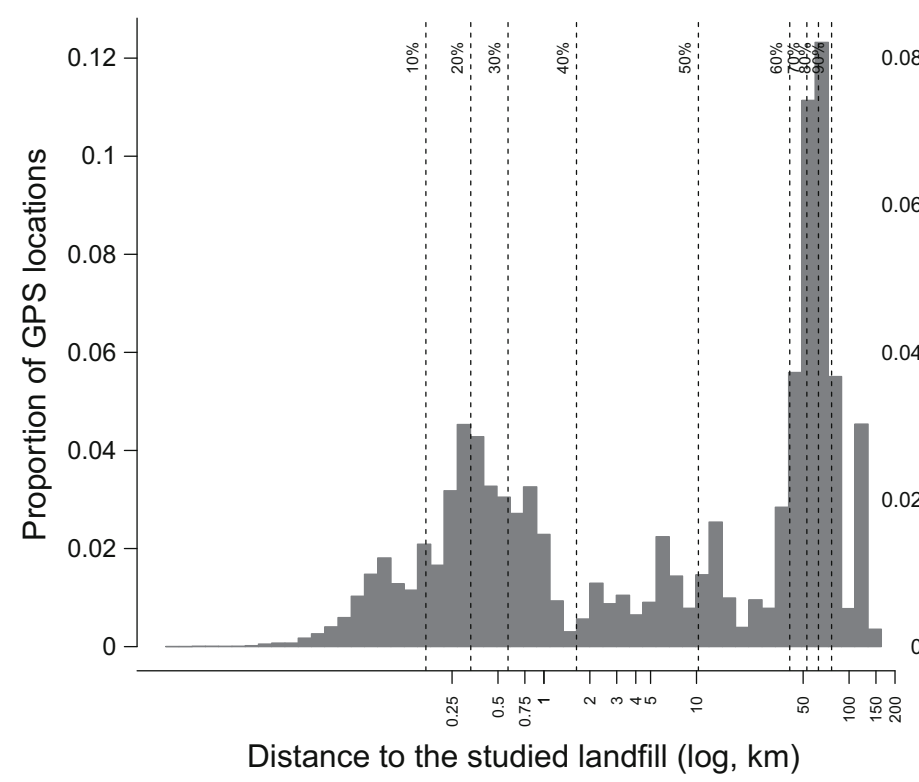

Fig. 6 Distances from the studied landfill (waste storage centre of SaintFlour, central France, log scale, $\mathrm{km}$ ) at which control ravens equipped with GPS trackers were located (A) during their whole monitoring, or (B) (b) only days with locations $<1 \mathrm{~km}$ from the landfill

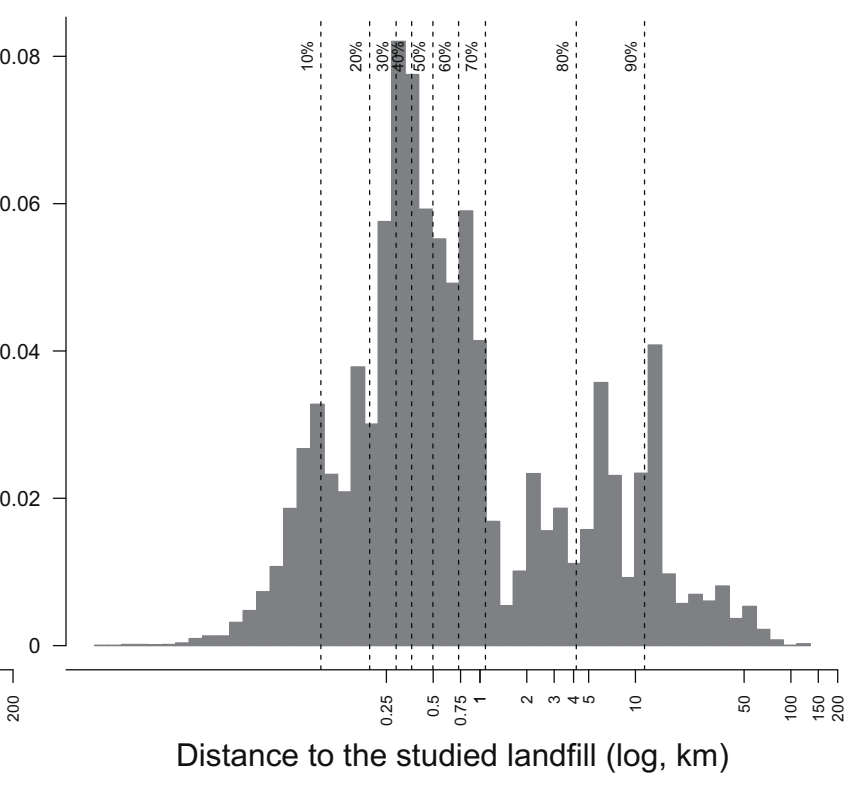

only days when they were considered present in the studied landfill, i.e. located at least once in the day at distances $<1 \mathrm{~km}$ recently observed in the Austrian Alps using GPS trackers (Loretto et al. 2016b, 2017). In addition, we found important and consistent seasonal variation in landfill use, movements, and more generally space use of non-breeding ravens. They were particularly attracted by the studied landfill and concentrated there during summer (June-September), whereas their presence decreased and their movements increased during September-March period. This seasonal pattern, also found in other raven populations, has been related to changes in the intensity of human activities in landfills (Ruiz-Olmo et al. 2006 in Spain), or to the presence of snow cover, to food scarcity and to the higher spread of food sources during winter (Loretto et al. 2016b in Austrian Alps).

All these results showed that the daily proportion of ravens in the landfill is just a small fraction of the entire population using this food source and varied seasonally. As a result, onetime/local management operations may affect only a limited proportion of the problematic population and consequently have a limited impact. More sporadic but repeated non-lethal shots at night roosts and surrounding foraging areas may probably affect a larger proportion of the population, but could be constrained in the long term by habituation (Bejder et al. 2009). In addition, disturbance at the main roost used by black vultures in Virginia was inefficient in reducing avian presence in areas used by livestock they depredated, as vultures only temporally shifted towards ancillary roosts during operations, but did not change space use during the day (Avery et al. 2006). Given the high number of roosts available within the large home range of ravens in this study, repeated disturbance in both main and ancillary roosts may be limited by operation costs and feasibility.

Homing behaviour was also revealed in relocated golden eagles and black vultures, leading relocations to fail in reducing predation concerns in most cases (Matchett and O'Gara 1987; Phillips et al. 1991; Humphrey et al. 2000). Only releasing birds at very large distances (several hundred kilometres) provided positive results but with expensive costs (Watte and Phillips 1994; Latta et al. 2003; Courchamp et al. 2003 in the specific case of an insular golden eagle population). More importantly, unsuccessful relocations might increase the spread of problematic individuals and their knowledge of the distribution of food sources in areas they did not visit before. As an example, after returning to the studied landfill, the two relocated ravens equipped with GPS trackers used larger areas than before and sometimes travelled out of the range occupied by control ravens, suggesting they might have included new areas in their home ranges as a result of relocations. However, in most areas used by other non-breeding flocks that we visited during our study, we often observed negative interactions with human activities (i.e. livestock/poultry predation, crop damage). This suggested that these problematic behaviours were not specific of ravens from the studied area but are rather widespread in non-breeding ravens. Interestingly, most of these interactions were ignored or unnoticed by humans/ farmers and were only identified in areas with very high densities of ravens. 
Table 2 General information and characteristics of movements and space use of control and relocated ravens equipped with GPS trackers in the waste storage centre of Saint-Flour (central France). Only data from individual ravens monitored during periods $>6$ months are provided. Avg dist. $/ \mathrm{h}=$ average distance $(\mathrm{km})$ per hour; Max dist. $/ \mathrm{h}=$ maximum distance $(\mathrm{km})$ per hour; Avg dist./day = average distance $(\mathrm{km})$ per day; Max dist./ day $=$ maximum distance $(\mathrm{km})$ per day; $\mathrm{HR}=$ home range area $\left(\mathrm{km}^{2}\right)$ computed using all the data available and a Biased Random Bridge approach (95\%; see methods); Periods = number of significant periods in space use of control ravens identified by the Lavielle approach (see methods); Avg. duration = average duration of the periods (days); Avg. area/period $=$ average area $\left(\mathrm{km}^{2}\right)$ used during these periods (computed using data collected during the focal period and a Biased Random Bridge approach, see methods). Area before/after return: area $\left(\mathrm{km}^{2}\right)$ used before/ after return in relocated ravens (computed using data collected during the focal period and a Biased Random Bridge approach, see methods)

\begin{tabular}{|c|c|c|c|c|c|c|c|c|c|c|c|c|c|c|}
\hline Status & id & Start date & End date & Fixes & $\begin{array}{l}\text { Avg } \\
\text { dist./ } \\
\mathrm{h}\end{array}$ & $\begin{array}{l}\text { Max } \\
\text { dist./ } \\
\mathrm{h}\end{array}$ & $\begin{array}{l}\text { Avg } \\
\text { dist./ } \\
\text { day }\end{array}$ & $\begin{array}{l}\text { Max } \\
\text { dist./ } \\
\text { day }\end{array}$ & HR & Periods & $\begin{array}{l}\text { Avg. } \\
\text { duration }\end{array}$ & $\begin{array}{l}\text { Avg. } \\
\text { area/ } \\
\text { period }\end{array}$ & $\begin{array}{l}\text { Area } \\
\text { before } \\
\text { return }\end{array}$ & $\begin{array}{l}\text { Area } \\
\text { after } \\
\text { return }\end{array}$ \\
\hline Control & DA284535 & $2015-10-27$ & 2018-01-18 & 9796 & 1.95 & 43.24 & 26.63 & 175.86 & 1814.07 & 5 & 162.80 & 780.19 & & \\
\hline Control & DA284540 & 2015-11-30 & $2017-10-15$ & 5866 & 2.92 & 50.32 & 32.29 & 187.68 & 1810.82 & 5 & 137.00 & 620.26 & & \\
\hline Control & DA284571 & $2015-08-31$ & 2018-01-17 & 9003 & 1.63 & 45.06 & 25.43 & 144.54 & 1704.01 & 6 & 145.00 & 747.94 & & \\
\hline Control & DA284588 & 2015-09-09 & 2016-10-08 & 4728 & 1.49 & 47.30 & 16.55 & 149.47 & 251.51 & 6 & 65.83 & 121.21 & & \\
\hline Control & DA284664 & $2016-07-26$ & 2018-01-18 & 7032 & 1.26 & 37.82 & 16.85 & 110.00 & 90.03 & 10 & 54.10 & 99.91 & & \\
\hline Control & DA284665 & $2016-07-26$ & 2018-01-18 & 6260 & 1.81 & 34.78 & 23.82 & 86.20 & 276.09 & 5 & 108.20 & 231.54 & & \\
\hline Control & DA284667 & 2016-09-24 & 2018-01-18 & 4677 & 1.40 & 23.00 & 19.05 & 62.11 & 83.89 & 6 & 80.17 & 41.59 & & \\
\hline Control & DA284668 & 2016-09-24 & 2018-01-18 & 5217 & 1.43 & 50.04 & 20.88 & 89.09 & 286.37 & 5 & 96.20 & 166.98 & & \\
\hline Control & DA284669 & $2017-02-10$ & 2018-01-18 & 4348 & 1.32 & 31.67 & 20.71 & 109.34 & 540.53 & 3 & 114.00 & 344.94 & & \\
\hline Control & DA284670 & $2017-02-10$ & 2018-01-18 & 4838 & 1.20 & 37.10 & 19.91 & 112.92 & 238.28 & 4 & 85.50 & 130.09 & & \\
\hline Control & DB118627 & 2015-04-10 & 2018-01-14 & 6510 & 1.57 & 42.93 & 21.85 & 133.11 & 1603.85 & 5 & 202.00 & 747.11 & & \\
\hline Relocated & DA284510 & 2015-09-24 & 2018-01-18 & 10,273 & 2.27 & 48.01 & 31.36 & 159.54 & 1096.81 & & & & 834.85 & 911.39 \\
\hline Relocated & DA284538 & $2015-10-31$ & 2016-05-07 & 2327 & 2.89 & 40.58 & 37.05 & 131.52 & 695.27 & & & & 365.10 & 598.64 \\
\hline Relocated & DA284546 & 2016-01-06 & 2018-01-18 & 9470 & 2.09 & 44.92 & 27.69 & 171.83 & & & & & & \\
\hline Relocated & DA284579 & 2015-09-01 & 2018-01-18 & 10,929 & 1.97 & 66.12 & 26.61 & 157.27 & 548.21 & & & & & \\
\hline Relocated & DB118650 & 2015-08-14 & 2016-11-21 & 5288 & 1.95 & 35.45 & 22.87 & 132.87 & 621.73 & & & & & \\
\hline
\end{tabular}

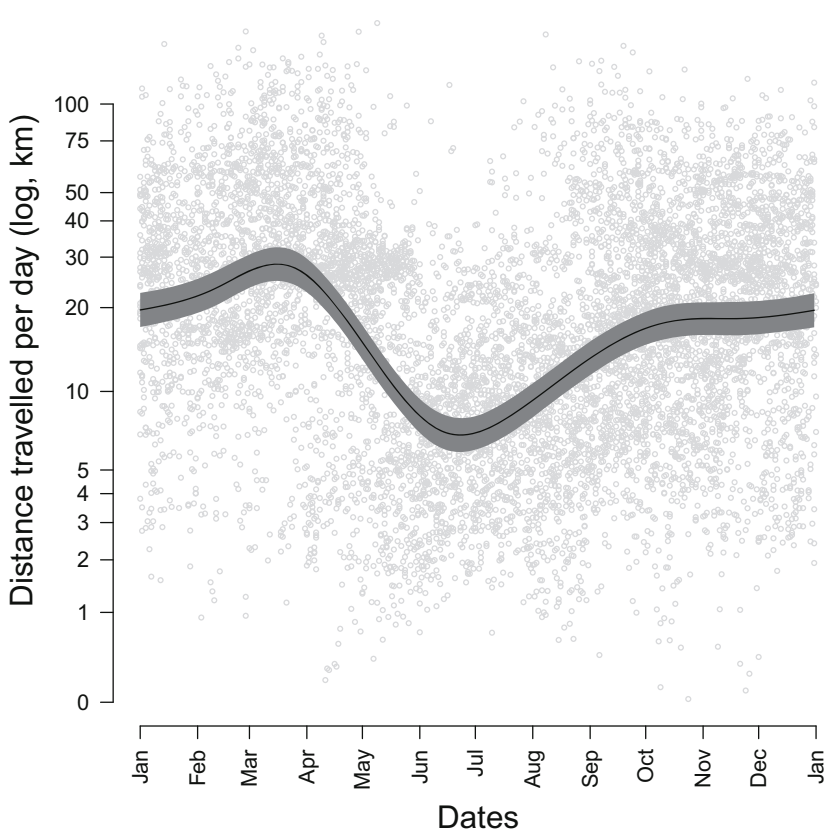

Fig. 7 Temporal variation in the distance travelled each day (log scale, $\mathrm{km}$ ) by control ravens equipped with GPS trackers. Light gray points represented raw data whereas the black line and the dark gray polygon represented predictions and $95 \%$ confidence intervals provided by a general additive mixed effect model (see methods)
Given that both approaches to sustainably disperse ravens failed, and that only few effective management experiments involving birds (corvids/raptors) and livestock have been reported in the literature, other levers for actions must be investigated (see Breitenmoser et al. 2005 for a review). Adjusting husbandry techniques, e.g. by reducing lambing season to a short period and guarding or enclosing lambs and ewes during this season, or decreasing the attractiveness of the landfill by preventing ravens from accessing waste, could be tested. However, in addition to the effectiveness of such management actions, social and economical components are two other cornerstones of depredation management that are still to be evaluated (Dickman 2010). In addition, a good knowledge about the ecology and the behaviour of the problematic species in areas where conflicts occur is hence an essential prerequisite for effective management. Here, by combining traditional mark-resight monitoring with innovative research systems (camera traps and GPS trackers), we were able to acquire essential information (e.g. evaluation of management approaches, range occupied by the population, seasonal variation in landfill use) about the problematic population in a reasonable time period (around 3 years). Data even suggested that a less intensive but continuous monitoring combining GPS trackers and observations of wing-tagged birds using camera traps deployed on the most attractive points in the landfill could have 
provided comparable results. By contrast, a monitoring relying only on leg rings and resightings through recaptures would not have provided the necessary information. As shown by the differences between recapture and resighting probabilities, young individuals were more likely to be captured whereas older ravens avoided traps despite being present and resighted in the landfill. Identifying leg-ringed birds on photos from camera traps was far more difficult than for wing-tagged individuals. Furthermore, as leg rings were deployed before wing tags (2013-2014 versus 2015-2016), leg-ringed ravens were more likely to have died or have dispersed during their monitoring period longer than the one of wing-tagged ones. This may partly explain the lower resighting probability recorded for leg-ringed birds compared with wing-tagged ones. Further research relying on CaptureMark-Recapture methods may help deciphering the relative contribution of demographic parameters (e.g. survival, emigration, immigration) and management operations in the variation of ravens abundance.

Finally, in this species with high cognitive skills including social learning and information transfer (Bugnyar 2013; Kulahci et al. 2016), understanding the role of sociality and movement behaviour in the ontogeny, the development and the transmission of livestock depredation behaviours may be of prime importance. In Spain, only a few individual ravens initially developed the specific behaviours leading to lamb predation but others quickly learned through observation (Ruiz-Olmo et al. 2006). Here, we observed that these problematic behaviours were widespread in the population, but their occurrence largely varied seasonally despite a high potential all year round as births in livestock farms were not synchronized during a limited period in the year (P. Lalo, personal communication). Despite essential information provided by our results, further research is needed to better understand why such conflicts occur and how to solve them. This is particularly important as raven populations increase, leading to a higher potential of conflicts with human activities (Boarman and Heinrich 1999b; Burfield and Van Bommel 2005).

Acknowledgements We warmly thank D. Dalle, T. Baguet and all the professionals from the ONCFS (Service Départemental 15, J. Duhayer, E. Petit, K. Ollivo, Q. Le Bayon, A. Séverac) and from the SYTEC (J. Jin, J. Rivoire and G. Verheyde) for their technical support in trapping, tagging and monitoring common ravens. We gratefully acknowledge J.-M. Cugnasse and M. Garel for useful advice for the monitoring of this population and data analysis, and two anonymous reviewers for their very helpful comments on previous drafts of this paper.

Funding This study was partially funded by the Direction Régionale de l'Environnement, de l'Aménagement et du Logement Auvergne-RhôneAlpes (A. Piel), and the Direction Départementale des Territoires du Cantal (P. Lalo).

\section{Compliance with ethical standards}

Ethical approval All the ravens captured have been treated by professionals according to the ethical conditions detailed in the specific accreditations delivered by the Préfecture du Cantal (2011-0804, 20130273, 2014-369, 2015-194, 2015-1437, 2015-31-DDT, 2015-50-DDT, 2015-382-DDT, 2016-0403, 2016-327-DDT, and 2017-0505), after being approved by the Conseil National de Protection de la Nature (notice 10/ 584/EXP, 14/030/EXP, 14/963/EXP, 2015-10-23x01144, 2016-02$23 \times 00132$ and 2017-02-23x00451), in accordance with the French environmental code (Art. R421-15 to 421-31 and R422-92 to 422-94-1). Likewise, management operations were performed in accordance with the same accreditations. Capture, handling and marking were performed by qualified persons, under the authorization $\# 800$ delivered by the Centre de Recherches sur la Biologie des Populations d'Oiseaux (Muséum National d'Histoire Naturelle, Paris). We hence confirm that all applicable international, national and/or institutional guidelines for the care and use of animals were followed.

\section{References}

Adams CE, Lindsey KJ (2016) Urban wildlife management. CRC Press, Boca Raton

Anton V, Hartley S, Wittmer H, Geldenhuis A (2016) Using camera traps and citizen science to monitor wildlife in urban areas. In: Ecological Restoration Australasia Conference

Avery ML, Cummings J (2004) Livestock depredations by black vultures and golden eagles. Sheep Goat Res J 19:58-63

Avery ML, Humphrey JS, Tillman EA, Milleson MP (2006) Responses of black vultures to roost dispersal in Radford, Virginia. In: Proceedings of the 22nd Vertebrate Pest Conference

Bejder L, Samuels A, Whitehead H, Finn H, Allen S (2009) Impact assessment research: use and misuse of habituation, sensitisation and tolerance in describing wildlife responses to anthropogenic stimuli. Mar Ecol Prog Ser 395:177-185

Benhamou S (2011) Dynamic approach to space and habitat use based on biased random bridges. PLoS One 6:e14592

Blackwell BF, DeVault TL, Fernández-Juricic E, Gese EM, GilbertNorton L, Breck SW (2016) No single solution: application of behavioural principles in mitigating human-wildlife conflict. Anim Behav 120:245-254

Boarman W (2003) Managing a subsidized predator population: reducing common raven predation on desert tortoises. Environ Manag 32(2): 205-217

Boarman W, Heinrich B (1999a) Common raven Corvus corax. Birds N Am 476:1-32

Boarman W, Heinrich B (1999b) Common raven (Corvus corax). In: Rodewald PG (ed) The birds of North America, Ithaca: Cornell Lab of Ornithology, pp Retrieved from the Birds of North America: https://birdsna.org/Species-Account/bna/species/comrav

Braun A, Bugnyar T (2012) Social bonds and rank acquisition in raven nonbreeder aggregations. Anim Behav 84:1507-1515

Breitenmoser U, Angst C, Landry JM, Breitenmoser-Würsten C, Linnell JDC, Weber JM (2005) Non-lethal techniques for reducing depredation. In: Woodroffe R, Thirgood S, Rabinowitz A (eds) People and wildlife - conflict of coexistence, pp 49-71

Bugnyar T (2013) Social cognition in ravens. Comp Cogn Behav Rev 8: $1-12$

Burfield I, Van Bommel F (2005) Birds in Europe: population estimates, trends and conservation status. BirdLife International, Cambridge

Cagnacci F, Boitani L, Powell RA, Boyce MS (2010) Preface. In: Challenges and opportunities of using GPS-based location data in animal ecology. Philos Trans R Soc B 365:2155. https://doi.org/10. 1098/rstb.2010.0098

Calenge C (2006) The package "adehabitat" for the R software: a tool for the analysis of space and habitat use by animals. Ecol Model 197: 516-519 
Conover M (2002) Resolving human-wildlife conflicts: the science of wildlife damage management. CRC Press, Boca Raton

Courchamp F, Woodroffe R, Roemer G (2003) Removing protected populations to save endangered species. Science 302(5650):1532-1532

Cushing JE (1941) Winter behavior of ravens at Tomales bay, California. Condor 43(2):103-107

Davies RAG (1999) The extent, cost and control of livestock predation. J Raptor Res 33(1):67-72

Delestrade A (2002) Biologie de la reproduction et distribution du grand corbeau Corvus corax en corse. Alauda 70:293-300

Demongin L (2005) Guide d'identification des oiseaux en main - Les 250 espèces les plus baguées en France

DeStefano S, DeGraaf RM (2003) Exploring the ecology of suburban wildlife. Front Ecol Environ 1:95-101

Dickman AJ (2010) Complexities of conflict: the importance of considering social factors for effectively resolving human-wildlife conflict. Anim Conserv 13:458-466

Donázar JA, Cortés-Avizanda A, Fargallo JA, Margalida A, Moleón M, Morales-Reyes Z, Moreno-Opo R, Pérez-García JM, SánchezZapata JA, Zuberogoitia I, Serrano D (2016) Roles of raptors in a changing world: from flagships to providers of key ecosystem services. Ardeola 63(1):181-234

Gehrt S, Riley S, Cypher B (eds) (2010) Urban carnivores: ecology, conflict, and conservation. John Hopkins University Press, Baltimore

Haffer J, Kirchner H (1993) Corvus corax. In: Handbuch der vögel mitteleuropas, AULA-Verlag, Wiesbaden, pp 1947-2022

Heinrich B, Kaye D, Knight T, Schaumburg K (1994) Dispersal and association among common ravens. Condor 96:545-551

Humphrey JS, Avery ML, McGrane AP, et al (2000) Evaluating relocation as a vulture management tool in North Florida. In: Vertebrate Pest Conference, vol 19, pp 49-53

Kristan WB, Boarman W (2003) Spatial pattern of risk of common raven predation on desert tortoises. Ecology 84:2432-2443

Kulahci IG, Rubenstein DI, Bugnyar T, Hoppitt W, Mikus N, Schwab C (2016) Social networks predict selective observation and information spread in ravens. R Soc Open Sci 3(7):160256

Latta BC, Driscoll DE, Linthicum JL, Jackman RE, Doney G (2003) Capture and translocation of golden eagles from the California channel islands to mitigate depredation of endemic island foxes. In: Proceedings of the sixth California Islands Symposium

Lavielle M (1999) Detection of multiple changes in a sequence of dependent variables. Stoch Process Appl 83:79-102

Lavielle M (2005) Using penalized contrasts for the change-point problem. Signal Process 85:1501-1510

Loretto MC, Reimann S, Schuster R, Graulich D, Bugnyar T (2016a) Shared space, individually used: spatial behaviour of non-breeding ravens (Corvus corax) close to a permanent anthropogenic food source. J Ornithol 157:439-450

Loretto MC, Schuster R, Bugnyar T (2016b) Gps tracking of non-breeding ravens reveals the importance of anthropogenic food sources during their dispersal in the eastern alps. Curr Zool 62:337-344

Loretto MC, Schuster R, Itty C, Marchand P, Genero F, Bugnyar T (2017) Fission-fusion dynamics over large distances in raven non-breeders. Sci Rep 7(1):380

Lowry H, Lill A, Wong B (2012) Behavioural responses of wildlife to urban environments. Biol Rev 88:537-549

Madden CF, Arroyo B, Amar A (2015) A review of the impacts of corvids on bird productivity and abundance. Ibis 157:1-16

Margalida A, Colomer M (2012) Modelling the effects of sanitary policies on European vulture conservation. Sci Rep 2:753

Margalida A, Campión D, Donázar JA (2014) Vultures vs livestock: conservation relationships in an emerging conflict between humans and wildlife. Oryx 48(2):172-176

Marzluff JM (2001) Worlwide urbanization and its effects on birds. In: Marzluff JM, Bowman R, Donnelly R (eds) Avian ecology and conservation in an urbanizing world, pp 19-47
Matchett MR, O'Gara BW (1987) Methods of control golden eagle depredation on domestic sheep in southwestern Montana. J Raptor Res 21:85-94

Messmer T (2000) The emergence of human-wildlife conflict management: turning challenges into opportunities. Int Biodeterior Biodegrad 45:97-102

Mure M (2014) Espèces protégées et activités humaines - Suivi de population de grands corbeaux (Corvus corax) dans le département du Cantal, analyse des mesures d'effarouchement et de gestion mises en œuvre pour résoudre les difficultés rencontrées par cette espèce. Tech. rep., Université Claude Bernard Lyon 1

Palumbi SR (2001) Humans as the world's greatest evolutionary force. Science 293:1786-1790

Peterson S, Colwell M (2014) Experimental evidence that scare tactics and effigies reduce corvid occurrence. Northwest Nat 95:103-112

Phillips RL, Blom FS (1988) Distribution and magnitude of eagle/ livestock conflicts in the western United States. In: Proceedings of the Thirteenth Vertebrate Pest Conference

Phillips RL, Cummings JL, Berry JD (1991) Responses of breeding golden eagles to relocation. Wildl Soc Bull 19:430-434

R Development Core Team (2017) R: a language and environment for statistical computing. R foundation for statistical computing, Vienna

Ratcliffe D (1997) The raven. Poyser, London

Restani M, Marzluff JM, Yates RE (2001) Effects of anthropogenic food sources on movements, survivorship, and sociality of common ravens in the arctic. Condor 103:399-404

Rösner S, Selva N (2005) Use of the bait-marking method to estimate the territory size of scavenging birds: a case study on ravens Corvus corax. Wildl Biol 11:183-191

Rösner S, Selva N, Müller T, Pugacewicz E, Laudet F (2005) Raven Corvus corax ecology in a primeval temperate forest. Corvids of Poland Bogucki Wyd, Nuak, Poznan pp 385-405

Rowley I (1969) An evaluation of predation by 'crows' on young lambs. Wildl Res 14:153-179

Ruiz-Olmo J, Dalmau Gafas Q, Bosch Ricart J, Masoller Arias J, Cárdenas Cobos G (2006) Daños del cuervo al ganado ovino en cataluña. dimensiones del problema y criterios de gestión. Quercus (246):18-24

Skarphedinsson K, Nielsen O, Thorisson S, Thorstensen S, Temple S (1990) Breeding biology, movements, and persecution of ravens in Iceland. Acta Naturalia Islandica 33(1):45

Thirgood S, Woodroffe R, Rabinowitz A (2005) The impact of humanwildlife conflict on human lives and livelihoods. In: Woodroffe R, Thirgood S, Rabinowitz A (eds) People and wildlife - conflict of coexistence, pp 13-26

US Department of the Interior Fish and Wildlife Service, US Department of Agriculture Animal and Plant Health Inspection Service and US Department of Defense, US Department of the Interior Bureau of Land Management CDD (2008) Environmental assessment to implement a desert tortoise recovery plan task: reduce common raven predation on the desert tortoise. Tech Rep

Vitousek PM, Mooney HA, Lubchenco J, Melillo JM (1997) Human domination of earth's ecosystems. Science 277:494-499

Watte BC, Phillips RL (1994) An approach to controlling golden eagle predation on lambs in South Dakota. In: Proceedings of the Sixteenth Vertebrate Pest Conference, $\mathrm{p} 66$

Webb W, Boarman W, Rotenberry J (2004) Common raven juvenile survival in a human-augmented landscape. Condor 106:517-528

Webb W, Boarman W, Rotenberry J (2009) Movements of juvenile common ravens in an arid landscape. J Wildl Manag 73:72-81

Wiltschko R, Wiltschko W (2003) Avian navigation: from historical to modern concepts. Anim Behav 65:257-272

Wood SN (2006) Generalized additive models: an introduction with R. Chapman \& Hall/CRC Press, Boca Raton

Woodroffe R, Thirgood S, Rabinowitz A (eds) (2005) People and wildlife-conflict or coexistence, no. 9 in Conservation Biology. Cambridge University Press, Cambridge 